\title{
A New Method of Designing Double-tuned Filter
}

\author{
HE Yi-hong, SU Heng \\ Information Engineering College of $\mathrm{Wu}$ Yi University \\ Jiangmen 529020, China \\ hyh@mail.wyu.edu.cn
}

\begin{abstract}
Aiming at the question of parameter of double-tuned filter, A new method of designing double-tuned filter is proposed based on resonance frequency, by using the relationship that the impedance of double-tund filter and two parallel single tuned filters is equal and the resonance frequency of single tuned filter is the zero of the impedance of double-tuned filter. Simulation results show that the doubletuned filter designed in this method works well. All of this has an important guiding significance for the research of doubletuned filter.
\end{abstract}

Keywords-double-tuned filter; impedance characteristics; series resonance frequency; parallel resonance frequency;

\section{INTRODUCTION}

Passive filter has been widely used in filtering harmonics in power system by now, because it has a simple structure, low cost, high reliability, and so on. Usually, there are multiple frequency harmonics in a power system, so a group of parallel single tuned filters are needed to filter harmonics. This filtering method covers a large area and has a high cost. Double-tuned filter and two parallel single tuned filters have the same function that both of them can filter two different frequency harmonics. However, double-tuned filter has a lower cost than the two parallel single tuned filters[1].

Now, researches on double-tuned filter attract people's attention, such as $\operatorname{loss}^{[2]}$, controllability ${ }^{[3,4]}$, parameters calculation $^{[5,6,7]}$. Literature[5] firstly puts forward an algorithm about parameters calculation of double-tuned filter, but the operation process is complicated. Literature[6] is a new method on double-tuned filter parameters calculation, which was published four years ago. It needs to solve equations and contains a large amount of computation.

Aiming at parameters calculation of double-tuned filter, a new method is proposed based on resonance frequency. It does not need to solve equations, so it reduces the amounts of computation. The correctness of this method is proved in a power system simulation.

\section{WORKING PRINCIPLE OF DOUBLE-TUNED FILTER}

The conventional double-tuned filter is composed of series resonance circuit and parallel resonance circuit. The structure and frequency impedance characteristic curve of traditional double-tuned filter are shown in Figure 1.

Series resonance circuit $\left(L_{1}, C_{1}\right)$ and parallel resonance circuit $\left(\mathrm{L}_{2}, \mathrm{C}_{2}\right)$ respectively have resonance frequency $\omega_{s}$ and $\omega_{p}$. They can be expressed as:

$$
\left[\begin{array}{l}
\omega_{s} \\
\omega_{p}
\end{array}\right]=\left[\begin{array}{l}
1 / \sqrt{L_{1} C_{1}} \\
1 / \sqrt{L_{2} C_{2}}
\end{array}\right] .
$$
is

The impedance of double-tuned filter shown in Figure1

$$
\begin{aligned}
& Z=j \omega L_{1}+\frac{1}{j \omega C_{1}}+\left(j \omega C_{2}+\frac{1}{j \omega L_{2}}\right)^{-1} \\
& =\frac{\left(1-\frac{\omega^{2}}{\omega_{s}^{2}}\right)\left(1-\frac{\omega^{2}}{\omega_{p}^{2}}\right)-\omega^{2} L_{2} C_{1}}{j \omega C_{1}\left(1-\frac{\omega^{2}}{\omega_{p}^{2}}\right)}
\end{aligned}
$$

where $\omega$ is the angular frequency in radians.

The impedance of series resonance circuit can be
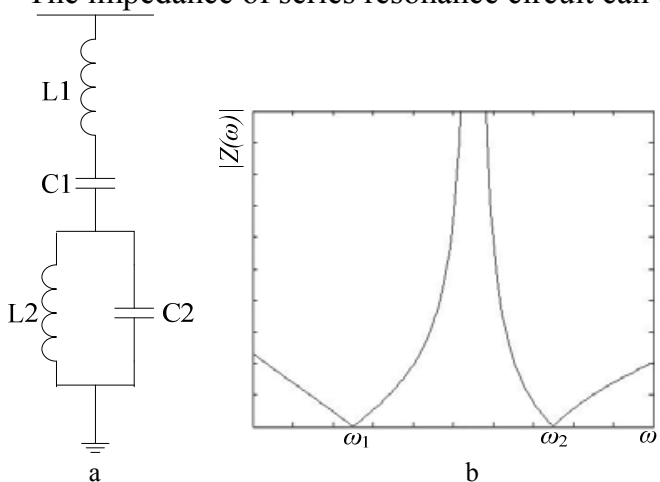

Figure 1. Double-tuned Filter Configuration and Impendence -frequency Characteristic Curve

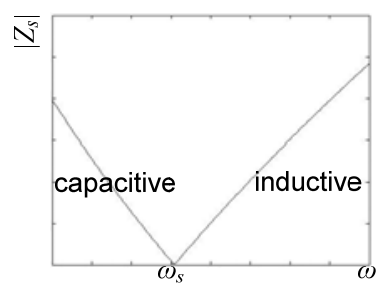

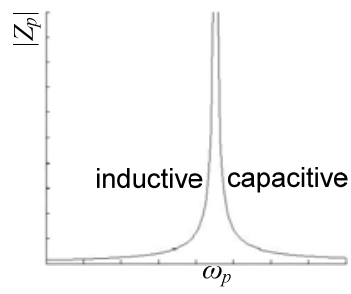

Figure 2. Impedance-frequency Curve of Series and Parallel Branch a)Series Resonance Circuit Impedance-frequency Characteristic Curve b)Parallel Resonance Circuit Impedance-frequency Characteristic Curve 
expressed as $Z_{s}=j \omega L_{1}+\frac{1}{j \omega C_{1}} . Z_{s}$ has a zero $\omega_{s .}$ When $\omega<\omega_{s}$, the impedance is capacitive; when $\omega>\omega_{s}$, it is inductive. The impedance of parallel resonance circuit can be expressed as $Z_{p}=\left(j \omega C_{2}+\frac{1}{j \omega L_{2}}\right)^{-1} \cdot Z_{p}$ has a pole $\omega_{p}$. when $\omega<\omega_{p}$, the impedance is inductive; when $\omega>\omega_{p}$, it is capacitive. Their frequency impedance characteristic curves are shown in Figure 2.

Picture b in Fig. 1 shows the superimposed characteristic curves of series and parallel branch, from which, another two tuned frequency, $\omega_{1}$ and $\omega_{2}$, can be seen clearly. At the two tuned frequencies, the total impedance of the filter is zero, so double-tuned filter can filter two different frequency harmonics.

\section{THE PARAMETERS CALCULATION OF DOUBLE-TUNED FILTER}

Two parallel single tuned filters are shown in Figure3. Their resonance frequencies respectively can be expressed as:

$$
\left[\begin{array}{c}
\omega_{a} \\
\omega_{b}
\end{array}\right]=\left[\begin{array}{l}
1 / \sqrt{L_{a} C_{a}} \\
1 / \sqrt{L_{b} C_{b}}
\end{array}\right]
$$

The impedance of two parallel single tuned filters can be expressed as:

$$
\begin{aligned}
& Z_{a b}=\left(\left(j \omega L_{a}+\frac{1}{j \omega C_{a}}\right)^{-1}+\left(j \omega L_{b}+\frac{1}{j \omega C_{b}}\right)^{-1}\right)^{-1} \\
& =\frac{\left(1-\frac{\omega^{2}}{\omega_{a}^{2}}\right)\left(1-\frac{\omega^{2}}{\omega_{b}^{2}}\right)}{j \omega C_{a}\left(1-\frac{\omega^{2}}{\omega_{b}^{2}}\right)+j \omega C_{b}\left(1-\frac{\omega^{2}}{\omega_{a}^{2}}\right)}
\end{aligned}
$$

Two parallel single tuned filters and double-tuned filter are equivalent, so their impedance are equal, $Z=Z_{a b}$. $Z$ has two zeros: $\omega_{a}$ and $\omega_{b}$. Formula (2) and (4) have the same

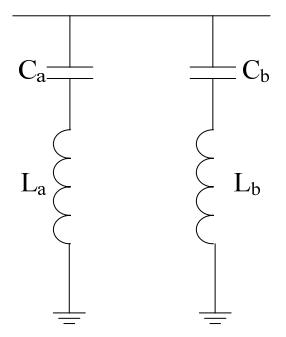

Figure 3. Parallel Single Tuned Filter constant term of 1 , so their molecular and denominator are equal respectively.

First of all, a set is defined as $S=\{a, b\}$. After analyzing the coefficient of $\omega^{4}$, we can gain an equation based on frequency, that is:

$$
\omega_{a} \omega_{b}=\omega_{s} \omega_{p}
$$

Analyzing the coefficient of $\omega$, we can find out the equation of

$$
C_{1}=C_{a}+C_{b}=\sum_{i \in S} C_{i}
$$

Analyzing the coefficient of $\omega^{3}$, we can find out that

$$
C_{b} \frac{1}{\omega_{a}^{2}}+C_{a} \frac{1}{\omega_{b}^{2}}=C_{1} \frac{1}{\omega_{p}^{2}}
$$
(7) :

The parameter of $L_{1}$ can be calculated from(1)、(5)、

$$
L_{1}=\frac{1}{C_{a} \omega_{a}^{2}+C_{b} \omega_{b}^{2}}=\frac{1}{\sum_{i \in S} C_{i} \omega_{i}^{2}}
$$

Using $L_{1} 、 C_{1}$, we can calculate series resonance frequency $\omega_{s}$ and parallel resonance frequency $\omega_{s}$, their frequencies can be obtained:

$$
\begin{aligned}
& \omega_{s}=\frac{1}{\sqrt{L_{1} C_{1}}}, \\
& \omega_{p}=\frac{\omega_{a} \omega_{b}}{\omega_{s}} .
\end{aligned}
$$

Since $\omega_{a}$ is the zero of double-tuned filter impedance, so $Z\left(\omega_{a}\right)=0$. The equation to solve $L_{2}$ is as follow:

$$
\left(1-\frac{\omega_{a}^{2}}{\omega_{s}^{2}}\right)\left(1-\frac{\omega_{a}^{2}}{\omega_{p}^{2}}\right)-\omega_{a}^{2} L_{2} C_{1}=0
$$
it is

Equation(11) can be simplified to get the value of $L_{2}$. And

$$
L_{2}=\frac{\left(1-\frac{\omega_{a}^{2}}{\omega_{s}^{2}}\right)\left(1-\frac{\omega_{a}^{2}}{\omega_{p}^{2}}\right)}{C_{1} \omega_{a}^{2}}
$$


We also can solve $L_{2}$ by using $\omega_{b}$. The two results are the same.

From (10)、(12), the value of $C_{2}$ can be obtained from the following equation:

$$
C_{2}=\frac{1}{L_{2} \omega_{p}^{2}}
$$

All of these equations above are included in the new method, in which we only need parameters of capacitances in the two parallel single tuned filters to solve parameters calculation of the double-tuned filter.

\section{POWER SYSTEM SIMULATION}

In this paper, the software MATLAB is used to simulate the double-tuned filter designed in this new method. There is a plating base in which harmonics pollution is serious. We can prove the correctness of this method in this case. Plating power supply turns power frequency alternating current into pulse current. It contains the $6 k \pm 1$ odd harmonic component, such as six pulse converter's AC side, so it contains the $6 k \pm 1$ odd harmonic current. The simulative power system configuration and the parameters of the component in the system are respectively shown in Figure 4 and TABEL I.

When the double-tuned filter is not put into the system, the current in A phase is shown in Figure 5. Adopting FFT to analyze the current of A phase, the percent of the $5^{\text {th }}$ wave current and $7^{\text {th }}$ wave current are separately $19.85 \%$ and $13.59 \%$, so that $5^{\text {th }}$ wave and $7^{\text {th }}$ wave account for a large proportion in the system.

When the filter is put into operation, the current of A phase is shown in Figure 6, and the current in the double- tuned filter is shown in Figure 7.

In the Figure 6 , the $5^{\text {th }}$ and $7^{\text {th }}$ wave are inhibited well in terms of the picture. After using FFT analysis, we can find out that the percent of $5^{\text {th }}$ and $7^{\text {th }}$ wave current are $1.38 \%$ and $0.74 \%$ separately. Figure 7 shows the $5^{\text {th }}$ wave current and $7^{\text {th }}$ wave current which the filter absorbs.

In order to see the filtering effect clearly, the comparison of total harmonic distortion(THD) is shown in Figure 8 and Figure 9. Fig. 8 shows the THD in the power system before filtering, while Fig.9 shows the after. Different from these figures before, they are expressed by bar in order to visually show the filtering effect. As shown in Fig.8, $5^{\text {th }}$ and $7^{\text {th }}$ wave content are obvious before the double-tuned filter is put into the system, and $5^{\text {th }}$ and $7^{\text {th }}$ wave content are close to zero after it works.

These figures that the simulation produced prove that $5^{\text {th }}$ and $7^{\text {th }}$ wave account for a large proportion before the double-tuned filter was put into operation, However, after the filter was put into operation, we found out that it had a good filtering effect.

TABLE I. COMPONENT PARAMETERS IN POWER SYSTEM

\begin{tabular}{cccc}
\hline 元件 & 参数设置 & 元件 & 参数设置 \\
\hline $\mathrm{AC} 1$ & $110 \mathrm{kV} 50 \mathrm{~Hz} 0$ & $\mathrm{~L} 3$ & $5 \mathrm{mH}$ \\
$\mathrm{AC} 2$ & $110 \mathrm{kV} 50 \mathrm{~Hz}-120$ & $\mathrm{C} 3$ & $500 \mu \mathrm{F}$ \\
$\mathrm{AC} 3$ & $110 \mathrm{kV} 50 \mathrm{~Hz}-240$ & $\mathrm{R} 5$ & $40 \Omega$ \\
$\mathrm{R} 4 、 \mathrm{R} 6 、 \mathrm{R} 7$ & $0.07 \Omega 108.28 \mu \mathrm{H}$ & $\mathrm{L}$ & $3 \mathrm{mH}$ \\
$\mathrm{C}$ & $40 \mu \mathrm{F}$ & $\mathrm{R} 1$ & $1000 \Omega$ \\
$\mathrm{R} 3$ & $100 \Omega$ & $\mathrm{R}$ & $1 \Omega$ \\
\hline
\end{tabular}

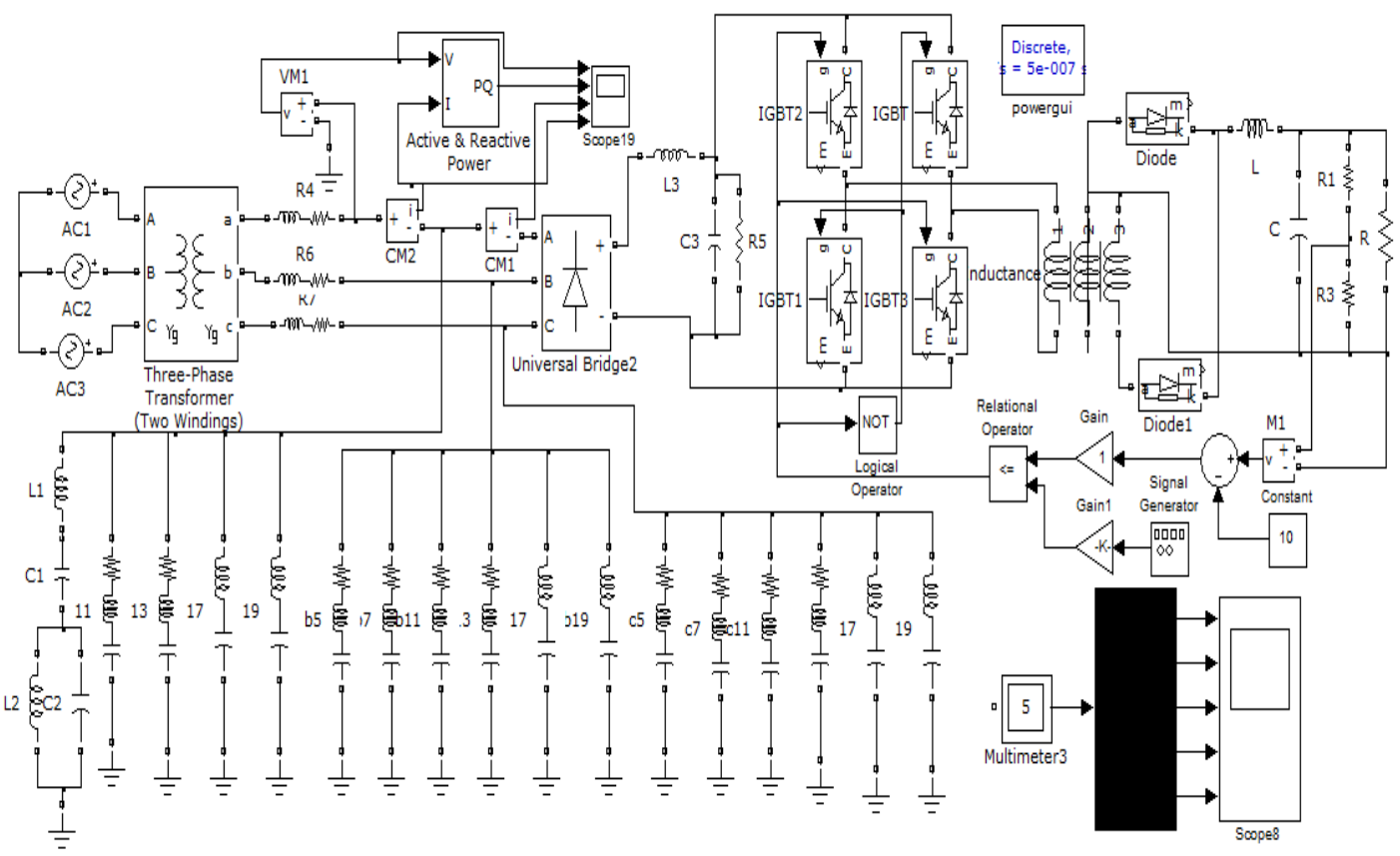

Figure 4. Simulative Power System Configuration 


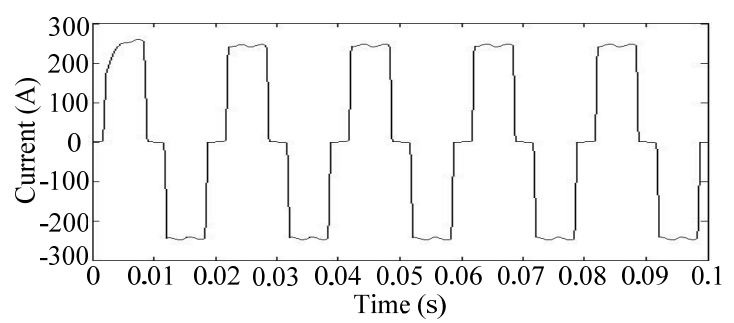

Figure 5. The Current of A Phase before Filtering

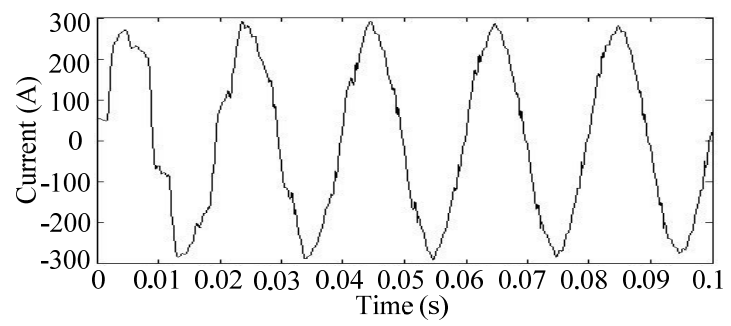

Figure 6. Current of A Phase after Filtering

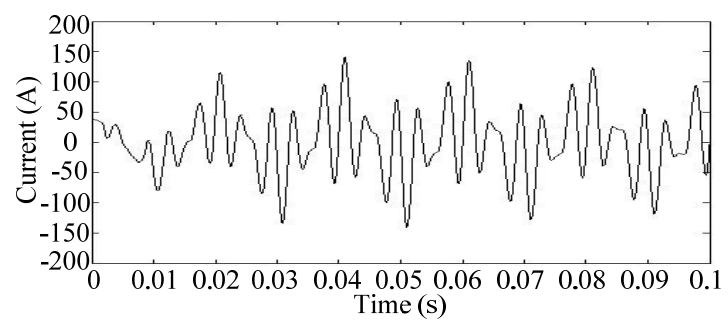

Figure $7.5^{\text {th }}$ and $7^{\text {th }}$ Wave in Double-tuned Filter.

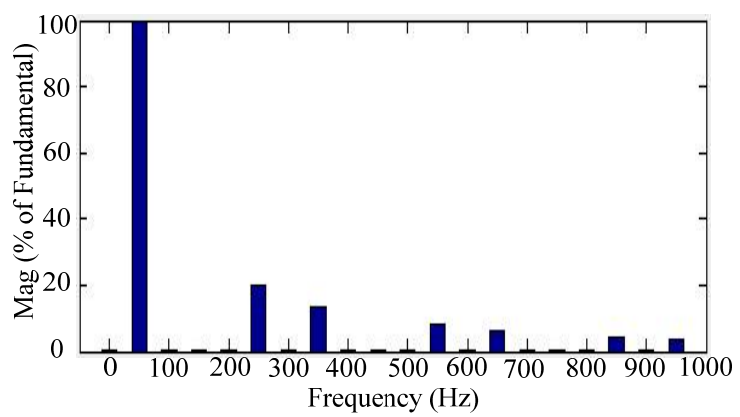

Figure 8. THD in A Phase before Filtering

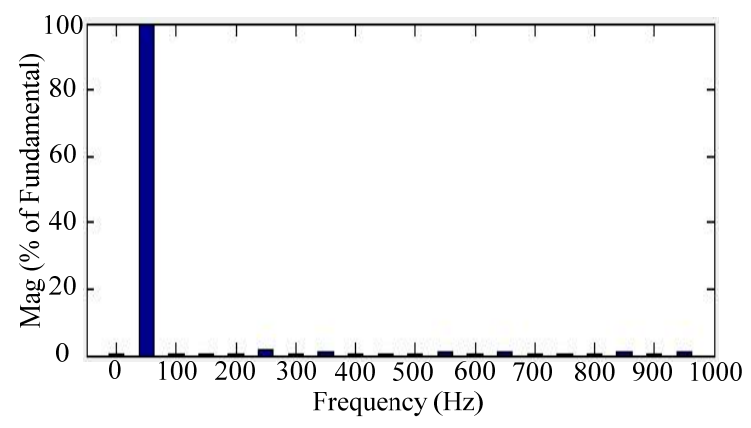

Figure 9. THD in A Phase after Filtering

\section{CONCLUSION}

This paper studies the parameters calculation of the double-tuned filter based on frequency and proposes a new idea in which we can get the parameters of double-tuned filter without solving equations, so it simplifies the operation. Double-tuned filter cost less than two parallel single tuned filters, so more economy will be produced. This new method has an important guiding significance for the research of double-tuned filter.

\section{REFERENCES}

[1] Wang Zhaoan, Yang Jun, etc. Harmonic Suppression and Reactive Power Compensation[M]. Beijing: CHINA MACHINE PRESS, 2010.

[2] XIAO Yao, SHANG Chun, etc. Multi-tuned Passive Filters with Less Power Loss[J]. Automation of Electric Power Systems, 2006, 19(30): 69-72.

[3] Kang Ming-cai, Zhou Jia-hua. Compensates the double tuned filter element parameter change based on controllable reactor[C]// Electricity Distribution, 2008. CICED 2008, 2008.

[4] Yu Ming tao, Chen Jianye, Wang Weian, Wang Zanji. A double tuned filter based on controllable reactor[C]// Power Electronics, Electrical Drives, Automation and Motion, 2006. SPEEDAM, 2006: 1232-1235.

[5] Xiao Yao. Algorithm for the Parameters of Double tuned Filter[J]. USA: IEEE, 1998, 1: 154-157.

[6] LI Pu-ming, XU Zheng, etc.Algorithm for the Parameters of AC Filters in HVDC Transmission System[J]. Proc. CESS, 2008, 16(28):115-120.

[7] Kang Ming-cai, Zhiqian Bo, Xiping Zhao. The Parameters Calculation and Simulation Research about Two Types Structure of Double-tuned Filter[C]// Universities Power Engineering Conference(UPEC), 2010 45th International. 2010: 1-4. 